\title{
Distal Humeral Morphology Indicates Locomotory Divergence in Extinct Giant Kangaroos
}

\author{
Billie Jones $^{1} \cdot$ Alberto Martín-Serra $^{2}$ ([) $\cdot$ Emily J. Rayfield ${ }^{1}\left[\right.$ C Christine M. Janis $s^{1,3}$
}

Accepted: 18 September 2021 / Published online: 9 November 2021

(c) The Author(s) 2021

\begin{abstract}
Previous studies of the morphology of the humerus in kangaroos showed that the shape of the proximal humerus could distinguish between arboreal and terrestrial taxa among living mammals, and that the extinct "giant" kangaroos (members of the extinct subfamily Sthenurinae and the extinct macropodine genus Protemnodon) had divergent humeral anatomies from extant kangaroos. Here, we use 2D geometric morphometrics to capture the shape of the distal humerus in a range of extant and extinct marsupials and obtain similar results: sthenurines have humeral morphologies more similar to arboreal mammals, while large Protemnodon species (P. brehus and P. anak) have humeral morphologies more similar to terrestrial quadrupedal mammals. Our results provide further evidence for prior hypotheses: that sthenurines did not employ a locomotor mode that involved loading the forelimbs (likely employing bipedal striding as an alternative to quadrupedal or pentapedal locomotion at slow gaits), and that large Protemnodon species were more reliant on quadrupedal locomotion than their extant relatives. This greater diversity of locomotor modes among large Pleistocene kangaroos echoes studies that show a greater diversity in other aspects of ecology, such as diet and habitat occupancy.
\end{abstract}

Keywords Macropodidae $\cdot$ Sthenurinae $\cdot$ Protemnodon $\cdot$ Functional morphology $\cdot$ Humerus $\cdot$ Locomotion

\section{Introduction}

Kangaroos (Marsupialia: Diprotodontia: Macropodoidea) are renowned for their mode of locomotion - bipedal hopping (also known as saltation or ricochetal locomotion). The "poster child" of kangaroos is indeed a fairly large animal that hops, such as a red or grey kangaroo (Osphranter rufus or Macropus giganteus/fuliginosus, respectively). Nevertheless, extant kangaroos possess a diversity of body masses and locomotor modes. Species today range from the tiny musky rat-kangaroo (Hypsiprymnodon moschatus) at a body mass of $500 \mathrm{~g}$ to the red kangaroo at up to $90 \mathrm{~kg}$ (a large male); kangaroos occupy almost every available Australasian habitat, from closed rainforest to arid grassland

Christine M. Janis

christine_janis@brown.edu

1 School of Earth Sciences, University of Bristol, Bristol BS8 1RJ, UK

2 Departamento de Ecología Y Geología. Facultad de Ciencias, Universidad de Málaga, 29071 Málaga, Spain

3 Department of Ecology and Evolutionary Biology, Brown University, Providence, RI 02912, USA
(Kear et al. 2008). With the exception of H. moschatus, all extant kangaroos can hop, and all use some form of quadrupedal locomotion as a slow gait. However, not all kangaroos are habitual hoppers; most notably, the tree-kangaroos (Dendrolagus spp.), a relatively recent (Plio-Pleistocene) radiation of secondarily arboreal forms, can hop but do not do so regularly. Evidence suggests that kangaroo locomotor diversity was even greater in the past (Janis et al. 2014, 2020; Den Boer et al. 2019; Warburton and Prideaux 2021); this paper aims to investigate this further.

Macropodoidea (Marsupialia: Diprotodontia; Fig. 1) first appears in the fossil record in the late Oligocene after diverging from a possum-like ancestor in the late Eocene (Meredith et al. 2008). The group consists of four families: the $\dagger$ Balbaridae, the Hypsiprymnodontidae (including various extinct forms and the extant musky rat-kangaroo), the Potoroidae (bettongs, potoroos, and rat-kangaroos), and the Macropodidae; the last two families are sister taxa, sometimes ranked as subfamilies within the Macropodidae (e.g., Prideaux and Warburton 2010). The Macropodidae is divided into three subfamilies: Lagostrophinae (today only Lagostrophus fasciatus), the $†$ Sthenurinae, and the Macropodinae (all other extant macropodids and several 


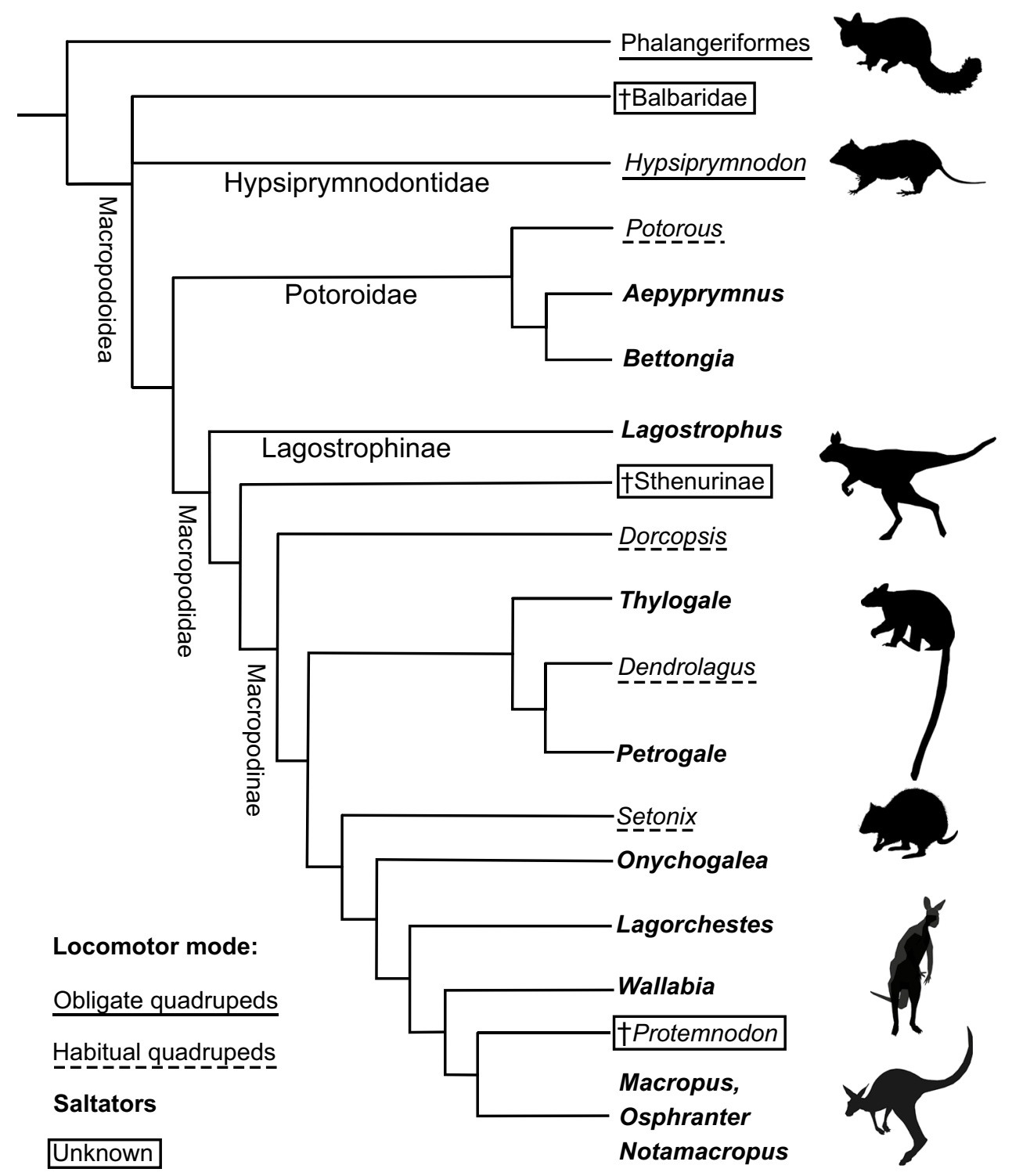

Fig. 1 Simplified schematic phylogeny of Macropodoidea modified from the molecular phylogeny of Llamas et al. (2015). Note that this phylogeny is just for display to illustrate the taxa studied and their interrelationships; no absolute time is implied. The position of the Balbaridae has been much debated (see Den Boer et al. 2019), and they have variably been placed as sister taxon to all extant macropodoids, sister taxon to the Hypsiprymnodontidae, or sister taxon to the Potoroidae + Macropodidae; we show them here in an unresolved trichotomy with Hypsiprymnodon and other extant macropodoids. (Note that if the Balbaridae are considered to be the sister taxon to extant forms, then the crown group is Macropodoidea and the total group is Macropodiformes.) "Habitual quadrupeds" represents macropodids that engage in predominantly quadrupedal terrestrial locomotion but are still capable of at least some hopping. A dagger symbol $(\dagger)$ indicates an extinct taxon. Sources for silhouettes: Hypsiprymnodon moschatus, Setonix brachyurus, and Trichosurus vulpecula from phylopic.org (credits: T. Michael Keesey, S. brachyurus photo taken by Sean Mack; images available for reuse under the Attribution-ShareAlike 3.0 Unported license https://creativecommons. org/licenses/by-sa/3.0/). All other silhouettes created by BJ using Inkscape, 2020. Osphranter rufus created from a composite of images in the public domain; Sthenurus stirlingi modified from Regal in Janis et al. (2014), with permission; Dendrolagus goodfellowi created from a photo taken by BJ of an animal in the Bristol Zoological Gardens; Protemnodon anak created from a photo taken by CMJ of the mounted specimen in the South Australian Museum extinct forms) (Prideaux and Warburton 2010; Llamas et al. 2015). Sthenurinae and Macropodinae had split by the middle Miocene (the date of the earliest known sthenurine), and both subfamilies experienced major radiations during the Plio-Pleistocene (Couzens and Prideaux 2018).
Some Plio-Pleistocene sthenurines and macropodines achieved "giant" size (in comparison to extant kangaroos, i.e., $>100 \mathrm{~kg}$ ). Sthenurines achieved estimated body masses of $54 \mathrm{~kg}$ (Procoptodon gilli) to $230 \mathrm{~kg}$ (Procoptodon goliah), with an average estimated mass of $120 \mathrm{~kg}$ (Helgen et al. 
2006). Giant macropodines include large species of Macropus (e.g., Macropus titan and Macropus ferragus at $\sim 150 \mathrm{~kg}$ (Helgen et al. 2006), plus an as yet unnamed species with a body mass estimate of $274 \mathrm{~kg}$ (Hocknull et al. 2020)), and their close relative, Protemnodon spp. (Fig. 1; Llamas et al. 2015). All species of Protemnodon were fairly large compared to extant kangaroos, with estimated body masses ranging from $40 \mathrm{~kg}$ (Protemnodon snewini) to $166 \mathrm{~kg}$ (Protemnodon roechus) (Helgen et al. 2006). Protemnodon species have long been considered to be simply "scaled-up" versions of large extant macropodines, but more recently their possible modes of locomotion have been questioned, with the suggestion that they may have been primarily quadrupedal forms (Den Boer 2018; Janis et al. 2020).

While almost all extant kangaroos use hopping for a fast gait (the only non-hopper being the musky rat-kangaroo, Hypsiprymnodon moschatus), the energetic difficulties of hopping slowly necessitate an alternative mode of slow locomotion; indeed, much of the daily locomotor repertoire of kangaroos is a slow, quadrupedal (or pentapedal) gait (O'Connor et al. 2014). Smaller kangaroos use a slow quadrupedal progression and also quadrupedal bounding (Windsor and Dagg 1971), while larger kangaroos use pentapedal locomotion (employed almost exclusively by large species of the genera Macropus and Osphranter; Dawson et al. 2015). During pentapedal locomotion, the tail is used as a fifth limb; it supports the body weight and propels the hind legs forward while the main body weight is borne on the forelimbs (O'Connor et al. 2014; Dawson et al. 2015). Pentapedal locomotion is extremely energetically inefficient. Linear increases of oxygen consumption with increasing speed during pentapedal locomotion are greater than those of quadrupedal bounding (Bennett 2000). Although large kangaroos are frequent hoppers, many smaller species hop rarely, if at all (e.g., the quokka, Setonix brachyurus; Windsor and Dagg 1971). Greater dependence on slow, quadrupedal locomotion has in fact evolved several times within Macropodoidea (Fig. 1). Consequently, though the majority of macropodoid locomotory adaptations are manifested in their long hindlimbs, their shorter forelimbs must also be adapted for at least some weight bearing during locomotion.

The optimal body mass for hopping locomotion is around $50 \mathrm{~kg}$ (Bennett and Taylor 1995). Studies of tendon strain in extant kangaroos have resulted in researchers proposing that hopping has a weight limit of around $150 \mathrm{~kg}$, calling into question whether the extinct giants in fact engaged in saltatorial locomotion (McGowan et al. 2008; Snelling et al. 2017; Doube et al. 2018). Anatomical evidence suggests sthenurines may have locomoted via a bipedal striding gait, using their hindlimbs alternatively (Janis et al. 2014). This form of locomotion has been proposed as at least an alternative for a slow quadrupedal gait, and trackway evidence does indeed provide evidence for a sthenurine striding bipedally
(Camens and Worthy 2019). Whether or not sthenurines used bipedal walking as an alternative to hopping is another issue entirely: smaller sthenurines may well have employed some hopping, although they lacked the anatomical specialties for rapid hopping seen in extant large kangaroos (Janis et al. 2014), but note that larger sthenurine species exceeded the proposed hopping weight limit previously mentioned.

Additional evidence for sthenurines not employing any quadrupedal gait comes from their forelimbs; the anatomy of the proximal humerus resembles that of suspensory arboreal mammals, while that of extant kangaroos resembles that of semi-arboreal (scansorial) forms (Janis et al. 2020). The sthenurine proximal humerus, with its globular humeral head and reduced tuberosities, therefore emphasizes mobility over support; this morphology would enable their proposed browsing behavior (Wells and Tedford 1995) but would limit their ability to bear weight on their forelimbs during slow locomotion (as would other aspects of their anatomy; see discussion in Janis et al. 2020).

Large species of Protemnodon (e.g., P. brehus, P. anak, P. roechus) also operated close to or above the biomechanical limits to hopping and far above the optimum body mass for hopping; yet little is known of how these taxa dealt with such locomotory constraints. Extinct animals do not always have extant analogues to which they can be compared, and attempting to shoehorn them into the ecological roles of extant animals may lead to underestimations of past morphological diversity. Although the postcranial morphology of Protemnodon generally resembles that of today's largest hopping kangaroos, there are some specific differences, as discussed below. Large Protemnodon species are often referred to as capable of full bipedal hopping (e.g., Kear et al. 2008), likely based on their phylogenetic proximity to Macropus and the similarities of the skull and dentition to modern day wallabies; indeed, Protemnodon is often referred to as a "giant wallaby."

The postcranial morphology of Protemnodon is unusual for a kangaroo. Protemnodon possessed extremely short feet (especially short metatarsals) (Fig. 2a-b; Den Boer 2018; Wagstaff 2018), a long neck (for a kangaroo), and unusually long and robust forelimbs (Den Boer 2018) (Fig. 2). The short feet are reminiscent of those of tree-kangaroos (Dendrolagus spp.) and are not conducive to sustained hopping, while saltatorial mammals in general have short necks to prevent locomotor whiplash (Hildebrand and Goslow 1982). The limb proportions of Protemnodon will be the subject of a further paper (although see Jones 2020); in this contribution, we will focus on the anatomy of the distal humerus.

We have seen that the anatomy of the proximal humerus supports locomotor behaviors for extinct giant kangaroos that are divergent from those of extant kangaroos. As previously described for the sthenurines, the morphology of the proximal humeral anatomy of Protemnodon (in both $P$. 
Fig. 2 Reconstruction of Protemnodon anak $(\sim 131 \mathrm{~kg}$; Helgen et al. 2006) based on a mounted specimen on display at the South Australian Museum. Drawing by BJ, based on a photo taken by CMJ. Average adult female human for size comparison (1.66 m). a, Metatarsal and the proximal, intermediate, and distal phalanges of the fourth hind digit of Protemnodon brehus (based on AMNH 145501), illustrating short metatarsal and robust nature of the phalanges. b, Metatarsal and the proximal, intermediate and distal phalanges of the fourth hind digit of Osphranter rufus $(\sim 50 \mathrm{~kg}$; Helgen et al. 2006) (based on UCMZ A12-21-3) for comparison of relative proportions and gracility. Scale bars represent $4 \mathrm{~cm}$. See Appendix Table 1 for museum abbreviations

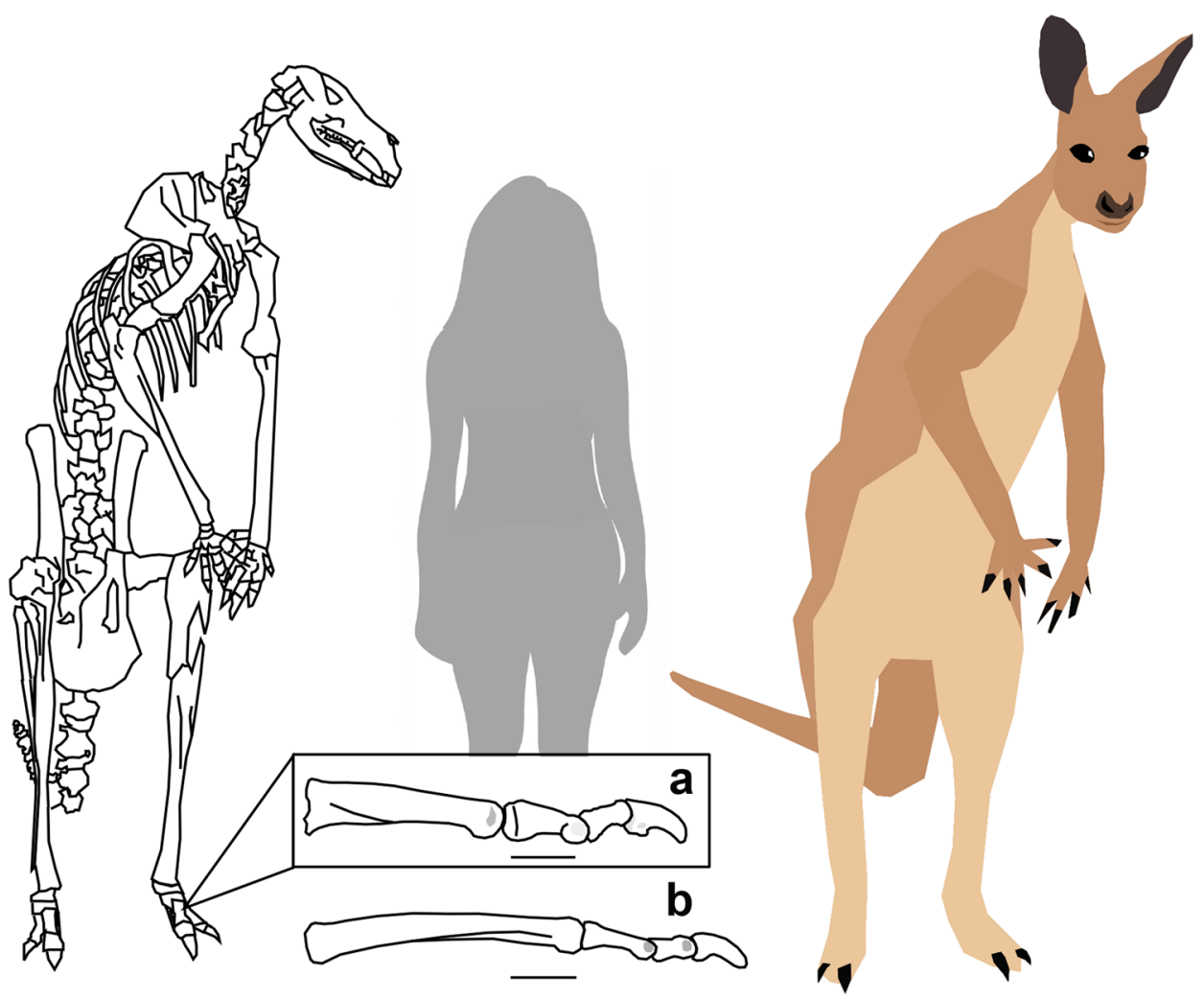

brehus and $P$. anak) is different from that of extant macropodids; it is more like that of a committed terrestrial mammal, with an ovoid humeral head and an enlarged greater tuberosity, indicating a significantly greater degree of weightbearing and stabilization for terrestrial locomotion than in extant macropodids (Janis et al. 2020).

The shape of the articular surface of the distal humerus reflects a number of aspects of forearm use, not only the capacity for rotation at the elbow joint (i.e., pronation and supination) versus the stability of this joint during load bearing, but also whether the arm is usually held in a flexed position (as in climbers) or in an extended one (as in terrestrial forms). The distal articulatory surface consists of the capitulum, which articulates with the radius, and the trochlea, which articulates with the ulna. More arboreal forms have a rounded capitulum and a relatively small and slender trochlea (Fig. 3a), reflecting the capacity to move the radius across the ulna in pronation and supination; more terrestrial forms have a flatter, spindle-shaped capitulum and an expanded, wedge-shaped trochlea (Fig. 3b), reflecting a more weight-bearing limb and a manus more restricted to the prone position. (See, e.g., Jenkins 1973; Taylor 1974; Argot 2001; Szalay and Sargis 2001; Andersson and Werdelin 2003; Polly 2007; Figueirido et al. 2016.)

In summary, the morphology of the distal surface of the humerus reflects the compromise between mobility and stability and so is a highly functional indicator of locomotion and substrate use that can be shown to discriminate among mammals based on their degree of forelimb mobility (Figueirido et al. 2016). In this paper, we investigate the morphology of the distal humerus in extinct giant kangaroos, comparing these with extant kangaroos and a diversity of other extant marsupials. We apply landmark-based analysis to determine if distal humeral morphology provides a further indication that kangaroo locomotor diversity was greater in the past.

\section{Materials and Methods}

\section{Materials}

The distal humeri of 77 marsupial individuals from 59 species (Appendix Table 1) were photographed in anterior view using either a Nikon SLR camera or FujiFilm FinePix S9900 W. Extremely small specimens were photographed using a Celestron Digital Microscope Pro connected to a MacBook Air.

Photographs of the distal humerus were standardized to the left-hand side; images of right humeri were mirrored if left humeri were unavailable. This study considered only marsupials among extant mammals due to notable morphological differences in distal humeral anatomy between arboreal marsupials and placentals (Figueirido et al. 2016). The study species comprised 25 extant and 11 extinct species 

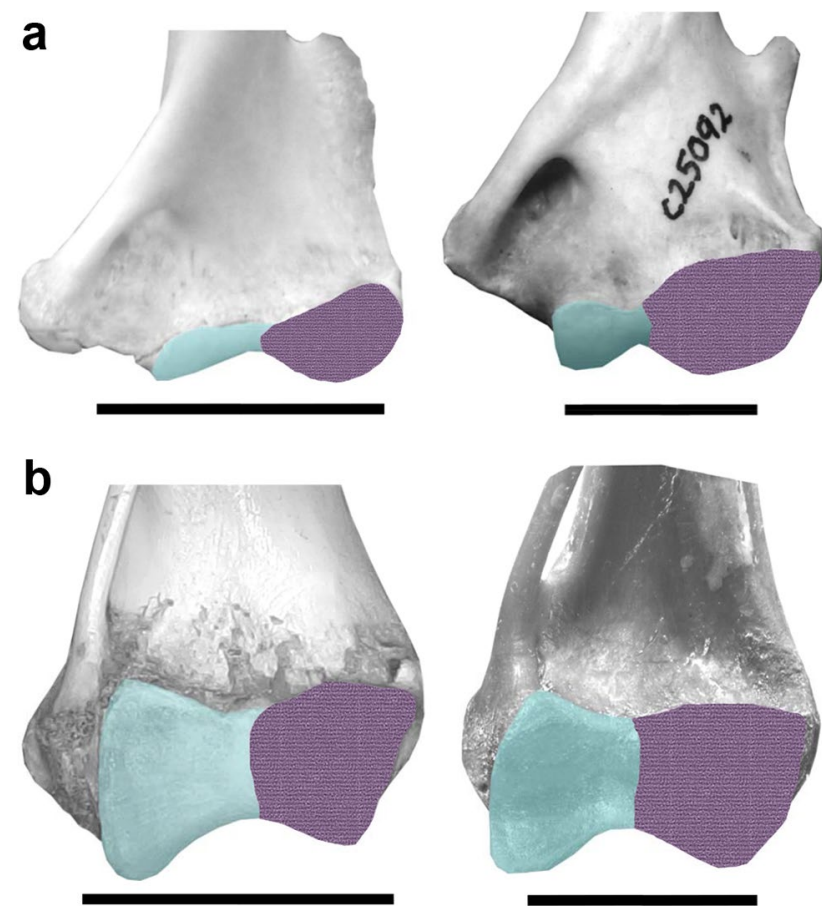

Fig. 3 The morphology of the distal humerus (anterior view) is reflective of forearm mobility and locomotor mode. a, Distal humeral morphology of arboreal marsupials, left: Phalanger orientalis (Northern common cuscus, AMNH 80933); right: Dendrolagus goodfellowi (Goodfellow's tree-kangaroo, NMV C25092). b, Humeral morphology of terrestrial marsupials, left: Sarcophilus harrisi (Tasmanian devil, AMNH 35634); right: Thylacinus cynocephalus (the thylacine, MCZ 36797). Trochlea = plain blue shading, capitulum $=$ speckled purple shading. See Appendix Table 1 for museum abbreviations

of macropodoids consisting of members of the families $\dagger$ Balbaridae, Hypsiprymnodontidae, Macropodidae, and Potoroidae, and 23 species of other extant or recently extinct marsupials from the following families: Dasyuridae, Didelphidae, Peramelidae, Petauridae, Phalangeridae, Phascolarctidae, Pseudocheiridae, $†$ Thylacinidae, Thylacomyidae, and Vombatidae.

Extinct macropodids included: two species of Protemnodon representing two different categories of body mass, Protemnodon anak $(\sim 131 \mathrm{~kg})$ and Protemnodon otibandus $(\sim 50 \mathrm{~kg}$; Helgen et al. 2006), plus an unnamed species from the Natural History Museum (London) of similar size to $P$. anak, five members of the subfamily Sthenurinae (Metasthenurus maddocki, Procoptodon gilli, Simosthenurus occidentalis, Sthenurus andersoni, and Sthenurus stirlingi); two large extinct Macropus (Macropus ferragus and Macropus sp.); and the balbarid Ganawamaya (= Nambaroo) gillespieae (proposed as terrestrial by Kear et al. (2007) and Den Boer et al. 2019).

It is common in studies on skeletal locomotor adaptations in mammals to refer to "locomotor categories" using terms such as "arboreal" (i.e., climbing), "scansorial" (i.e., semiarboreal), and "terrestrial" (i.e., ground-dwelling), even
Table 1 Results of the statistical analyses

i. Results of the phylogenetic signal using K multivariable for shape data

K $\quad$ Effect size $\quad p$

$\begin{array}{lll}0.2257 & 0.001 & 4.517\end{array}$

ii. Results of the phylogenetic Procrustes ANOVA. d.f.= degrees of freedom

$\begin{array}{llll}\text { Independent variable } & \mathbf{R}^{\mathbf{2}} & \text { d.f. } & \boldsymbol{p} \\ \text { Locomotor mode } & 0.076 & 2 & 0.029 \\ \text { Size } & 0.082 & 1 & 0.001 \\ \text { Size:Locomotor mode } & 0.028 & 2 & 0.793\end{array}$

iii. P-values obtained from the permutation test (10,000 iterations) performed for the morphological distances between the CVA groups

Mahalanobis distances Scansorial-

Terrestrial $<0.0001<0.0001$

Scansorial 0.0003

Procrustes distances

$\begin{array}{lll}\text { Terrestrial } & 0.0104 & <0.0001\end{array}$

Scansorial 0.0023

iv. Percent probability of classification of the "unknown" groups into each locomotor category in the CVA

\begin{tabular}{lllc} 
Group & \% Terrestrial & \% Scansorial & \% Arboreal \\
Saltatorial & 34.8 & 47.8 & 17.4 \\
Sthenurines & 20.62 & 10.46 & 68.92 \\
Protemnodon species & 21.36 & 75.35 & 3.29 \\
\hline
\end{tabular}

though such terms actually refer to substrate use rather than to locomotion per se (e.g., Van Valkenburgh 1985; Samuels and Van Valkenburgh 2008; Chen and Wilson 2015; Gould 2017). In all of these papers, "terrestrial" is taken to indicate generalized, unspecialized quadrupedal forms, and the categories "cursorial" (fast running; Gould 2017) and "ricochetal" or "saltatorial" (hopping; Samuels and Van Valkenburg 2008; Chen and Wilson 2015) may also be included in addition to "terrestrial", even though these forms are of course terrestrial in their habitat preference. We have followed this commonly-used terminology here in our locomotor categories while acknowledging that these are actually a combination of locomotor type and substrate use. We note that the terms "arboreal" and "terrestrial" also coincide with the degree of forearm use in locomotion (more mobile in arboreal climbers, more stabilized in terrestrial walkers and runners), as used by Figueirido et al. (2016).

Extant taxa were grouped into one of four categories using information from the literature: arboreal, scansorial, terrestrial, and saltatorial. The saltatorial group included all extant macropodids apart from the tree-kangaroos (classified as arboreal), and the obligate quadruped $H$. moschatus (classified as terrestrial) (extant macropodids have relatively high forearm mobility [Figueirido et al. 2016].) For the Procrustes 
ANOVA (see below), scansorial (semi-arboreal) taxa were grouped with either arboreal or terrestrial categories based on their preference for living in the canopy versus on the ground (predominantly arboreal or terrestrial, respectively; Appendix Table 1). For the canonical variates analysis, scansorial taxa were considered as their own category to allow a more intuitive visualization within a morphospace depicted by two canonical functions. The extinct species were classified as "unknown," with the exception of the two extinct species of Macropus that were classified as saltatorial, similar to the extant species of this genus.

\section{Methods}

Two-dimensional geometric morphometrics were employed to capture the shape of the distal humerus (Fig. 4a); a set of nine homologous landmarks (Fig. 4b; Appendix Table 2) were assigned in tpsDIGv2.32 (Rohlf 2004). A limited set of fixed landmarks was chosen because overload of dimensions

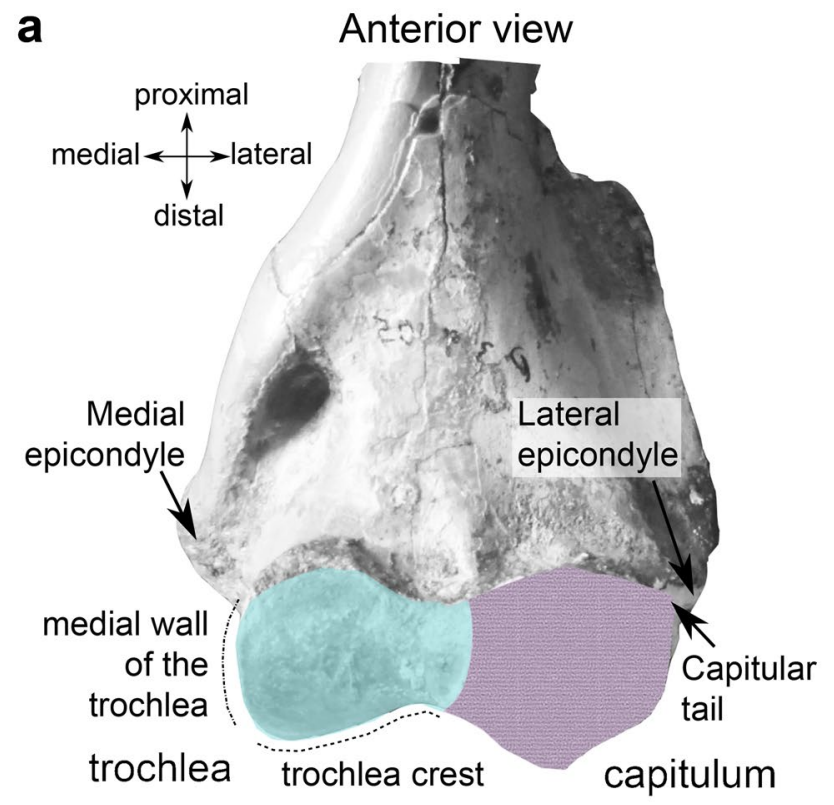

\section{b}

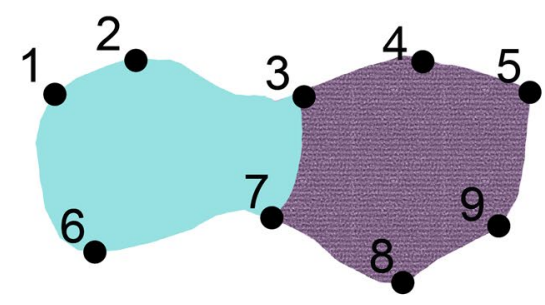

Fig. 4 Morphometric data collected. a, Anatomical diagram of the distal humerus of Protemnodon anak (NMV 39105), scale bar represents $2 \mathrm{~cm}$. b. Nine landmarks digitized onto the high-resolution photographs to capture the shape of the marsupial distal humerus. Trochlea $=$ plain blue shading, capitulum $=$ speckled purple shading is disadvantageous during subsequent analyses (Canonical Variates Analysis, see below; Mitteroecker and Bookstein 2011). The raw landmark coordinates were imported into R (R Core Team, 2020) and Procrustes alignment performed using the gpagen function in the package geomorph (Adams et al. 2016) to remove the effects of size, rotation, and translation.

First, the phylogenetic signal on the Procrustes coordinates was computed using a multivariate K-statistic with function physignal (Adams 2014) from geomorph package (Adams et al. 2016) in the R environment (R Core Team, 2020). In addition, we determined if these shape coordinates correlate with size and locomotor groups independently of phylogenetic structure. To do this, a phylogenetic Procrustes ANOVA (function procD.pgls) was performed on the Procrustes coordinates of extant taxa. Size was estimated using log-transformed centroid size and the phylogeny was obtained from vertlife.org (see supplementary information Fig. S1).

A principal components analysis (PCA) was then carried out on the Procrustes coordinates using the plotTangentSpace function. A canonical variates analysis (CVA) of the Procrustes coordinates was then executed in MorphoJ (Klingenberg 2011). Extant non-saltatorial taxa were separated into three groups: arboreal, scansorial, and terrestrial. A permutation test was carried out to test for the significance of the morphological differences between these groups, using both Mahalanobis and Procrustes distances (Klingenberg and Monteiro 2005). Following this, the CVA was repeated twice in IBM SPSS Statistics v.26 (this software yielded almost identical CVA results to MorphoJ [see Janis and Martín-Serra 2020]), separately adding in the extant saltatorial and extinct species of macropodoids as unknowns. This allowed a percentage of correct reclassifications to be calculated through leaving-one-out cross-validation and provided the probability of classification of the unknowns into each locomotor category. We were thus able to determine whether the distal humeri of the taxa in each unknown grouping are more similar to that of arboreal, scansorial or terrestrial taxa.

\section{Results}

The K-statistic for phylogenetic signal on shape variables yielded significant results, indicating that closely related species tend to be more similar than expected by random (Table 1i). However, the phylogenetic Procrustes ANOVA indicates that shape differences between locomotor groups are significant even after accounting for phylogeny (Table 1ii). Shape also shows significant correlation with size (allometry), but the interaction between size and locomotor grouping is not significant (Table 1ii), which indicates that the different categories have similar allometric patterns. 
The first two components of the PCA explain $56.55 \%$ of the total variance: $\mathrm{PC} 1=41.02 \%, \mathrm{PC} 2=15.53 \%$ (Fig. $5 \mathrm{a}$ ). Plots of other PC axes did not reveal any obvious morphological pattern. The positive extreme of the first component reflects a narrow, thin, and long trochlea and a more oval capitulum. The negative extreme of PC1 reflects a proximo-distally wide trochlea with a strong medial wall, separated from a proximo-distally wide capitulum by a deep sulcus (Fig. 5b). The first component distinguishes between the arboreal and terrestrial taxa, with arboreal taxa having positive scores and terrestrial taxa having negative scores (Fig. 5a).

Extant saltatorial macropodoids have scores on PC1 ranging from -0.09 to +0.08 and occupy an area intermediate between low forearm mobility (terrestrial taxa) and high forearm mobility (arboreal), similar to their position in other analyses of humeral morphology (Figueirido et al. 2016; Janis et al. 2020). The largest extant kangaroos, Macropus giganteus (\#51) and Osphranter rufus (\#59), are among the ones with the most positive scores, although the large extinct species of Macropus $(\# 50,52)$ have negative scores. Sthenurines plot on the positive end of PC1, mostly within the morphospace of the arboreal taxa, while Protemnodon species have slightly negative scores, falling more-or-less within the morphospace of the terrestrial taxa. The balbarid Ganawamaya (\#35) has a strongly negative score, more so than the sole extant terrestrial macropodoid Hypsiprymnodon (\#36).

The positive portion of the second component reflects a distal humerus with a medio-laterally short trochlea and a large, oval capitulum. The negative portion of PC2 reflects a long trochlea with a large trochlear crest and a small, rounded capitulum (Fig. 5b). PC2 appears to have a phylogenetic component; among the arboreal taxa, it
Fig. 5 PCA of distal humeral morphology. a, PCA performed on the 2D Procrustes coordinates of the distal humerus. Symbols differentiate different taxa, line style of the convex hulls indicate locomotor groups. Numbers identifying taxa are shown in Appendix Table 1. b, Deformation grids representing the shape change along PC1 and PC2. Grid deformation represents deformation from the consensus shape (PC score of 0.0 on both axes). Dasyuromorphia includes Dasyuridae and Thylacinidae; Didelphimorphia includes Didelphidae; Macropodoidea includes Balbaridae, Hypsiprymnodontidae, Macropodidae, and Potoroidae; Peramelemorphia includes Peramelidae and Thylacomylidae; Phalangeriformes includes Petauridae, Phalangeridae, and Pseudocheiridae; Vombatiformes includes Phascolarctidae and Vombatidae

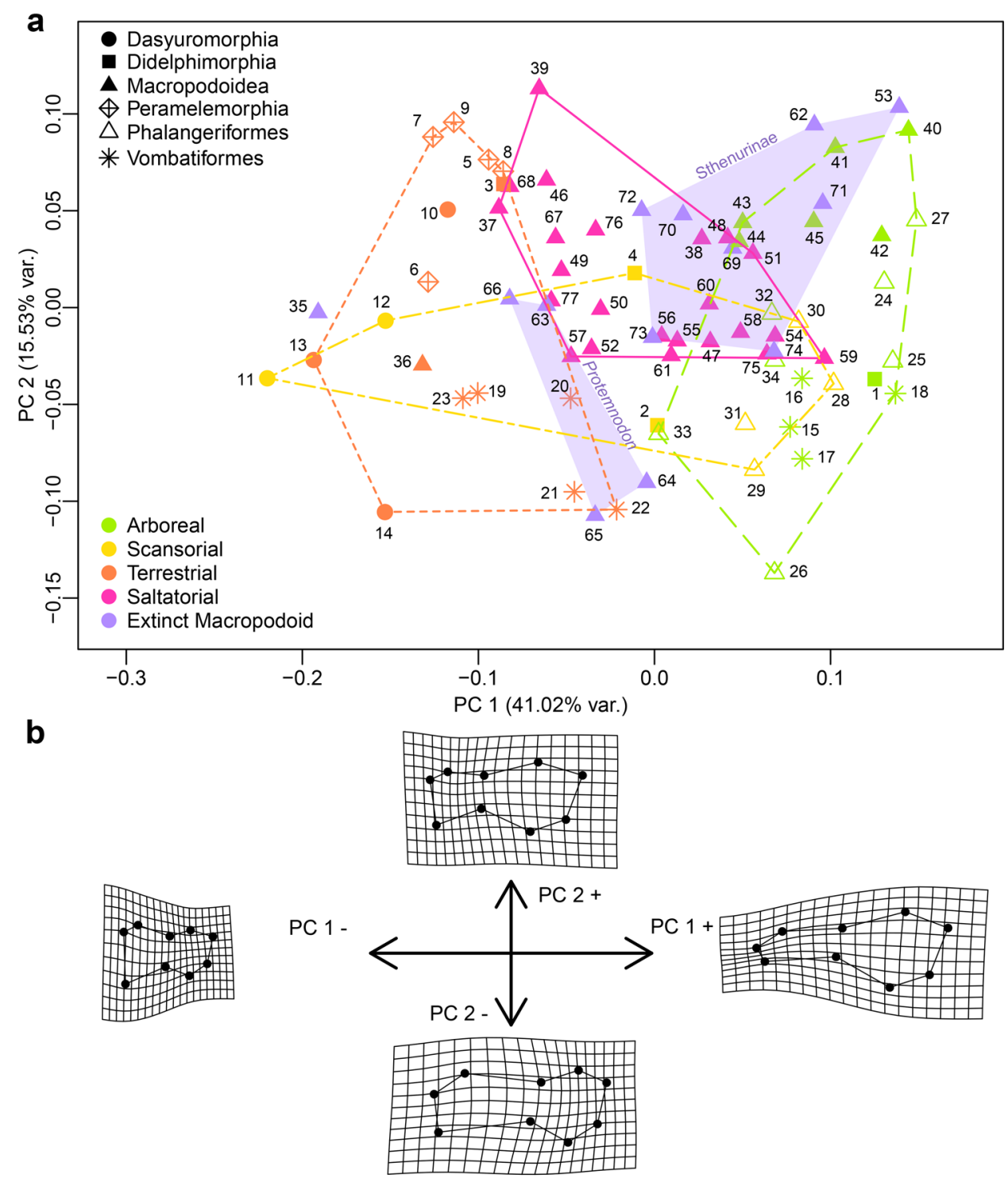


separates the tree-kangaroos (positive scores) from more specialized climbers (possums, cuscuses, opossums, and koalas, with negative scores); among the terrestrial forms, it separates the scansorial dasyuroids, didelphimorphs, and wombats (all Vombatus ursinus) (mostly negative scores) from the bandicoots and bilbies (positive scores); although the thylacine (\#10) groups with the bilbies, not with the related dasyurids. Most other macropodoids (excluding some Protemnodon species) have more positive scores (Fig. 5a).

The sthenurines, though their scores are divergent, plot almost entirely in the positive portions of both PC1 and PC2, most notably clustering with the large extant kangaroos and the tree-kangaroos. The distal humeri of the sthenurines, treekangaroos, and the large extant kangaroos resemble each other in that they all possess a larger, rounded capitulum with a much smaller, narrower and somewhat distally projecting trochlea. Protemnodon species cluster with the terrestrial taxa, specifically, the wombats. There appears to be large morphological variation within and between Protemnodon species; similar variability is seen among the wombat individuals (Fig. 5a).

Figure 6 shows the anatomy of the distal humerus of Protemnodon anak in comparison with that of some of the other study species. Compared to the common wombat (Vombatus ursinus; Fig. 6a), P. anak has a more pronounced capitular tail and a stronger and shorter medial wall of the trochlea. $P$. anak lacks the distal projection of the trochlea seen in wombats; however, the wombat capitulum is more spherical. The trochlea of $P$. anak is more proximo-distally extended than in the koala (Phascolarctos cinereus) (Fig. 6b), a sthenurine (Simosthenurus occidentalis) (Fig. 6c), and the red kangaroo (Osphranter rufus) (Fig. 6d), and also is more mediolaterally extended with a larger trochlear crest than seen in the latter two taxa. The capitular tail is more pronounced in $P$. anak than all three of these taxa.

The CVA (Fig. 7) classified taxa to their known locomotor group (terrestrial, scansorial and arboreal) with $87.8 \%$ accuracy (65.9\% with cross-validation). These groups show significant morphological differences (Table 1iii). The first axis explains $94.6 \%$ of the between-groups variance and separates arboreal taxa (positive scores) from terrestrial ones (negative scores), with scansorial taxa mostly in an intermediate position. The second axis explains only $5.4 \%$ of the between-groups variance; scansorial taxa have negative scores (or nearly so), while the scores of arboreal and terrestrial taxa are more variable. Table 1iv shows the percent classification of the "unknowns" into each of the locomotor groups.

Classification of the "unknown" taxa generally follows the pattern seen in the PCA. The saltatorial taxa mainly fall between the terrestrial and arboreal taxa on the first axis but have mostly higher scores on CV2 (Fig. 7a). A few species [including $O$. rufus, \#59) have positive scores on the first a

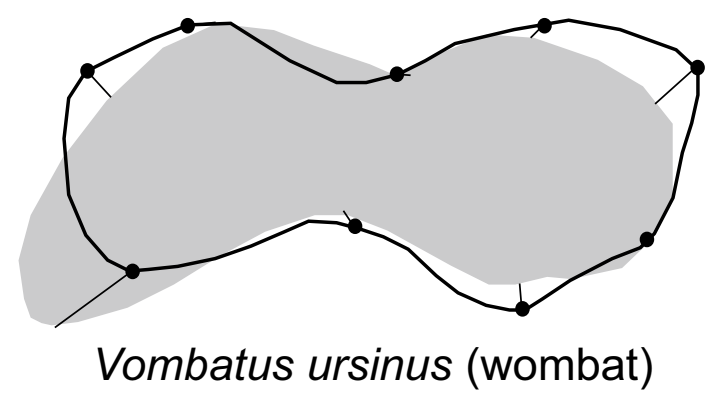

b

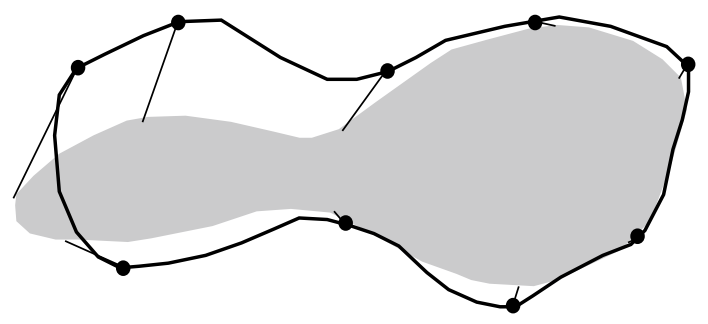

Phascolarctos cinereus (koala)

C

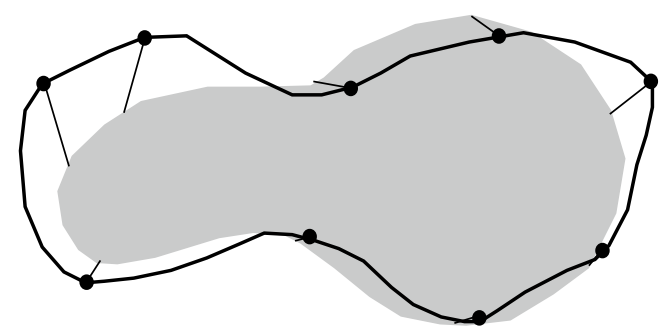

Simosthenurus occidentalis

d

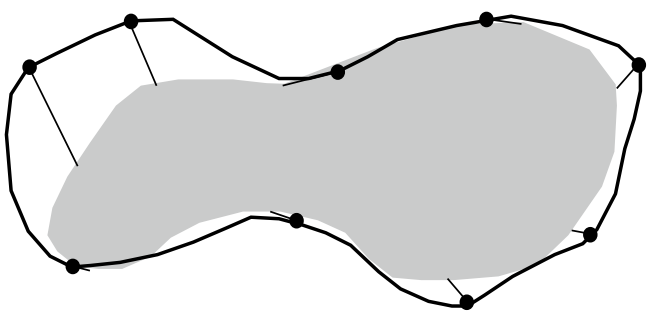

Osphranter rufus (red kangaroo)

Fig. 6 Morphometric comparison of the distal humeral anatomy of Protemnodon anak to other taxa. Diagrams represent lollipop graphs showing morphological change obtained from the distal humerus of Protemnodon anak (black outline) to the distal humerus of: a, common wombat (Vombatus ursinus). b, koala (Phascolarctos cinereus). c, sthenurine (Simosthenurus occidentalis). d, red kangaroo (Osphranter rufus)

axis, similar to the arboreal taxa but with more negative scores on the second component than any arboreal taxon, falling in the area of the morphospace occupied by the scansorial brushtail possum (Trichosurus vulpecula, \#30, 31); 
the reason for this placement is not clear). The sthenurines (\#53, 62, 69-74) cluster more toward the arboreal end of the first axis, although some of them (all belonging to the genus Sthenurus) have slightly negative scores and fall between arboreal and terrestrial morphospaces; however, they mostly have higher scores on PC2 than the extant taxa (Fig. 7b). The larger Protemnodon individuals (\#63, 64, 66) fall between terrestrial and arboreal morphospaces (Fig. 7b), but with negative scores on PC2 (while the saltatorial extant kangaroos mostly have positive scores). The small species of Protemnodon, P. otibandus (\#65), plot distant from the larger ones, within the arboreal morphospace but with very low scores on PC2 (again in a similar area to T. vulpecula) (Fig. 7b). The sole balbarid, Ganawamaya gillespieae (\#35), plots with terrestrial forms.

\section{Discussion}

Here we show that distal humeral morphology clearly distinguishes arboreal and terrestrial taxa among extant marsupials, echoing the study of Figueirido et al. (2016), which considered mainly placentals. Applying this to extinct macropodoids, we show that there was greater diversity of locomotor diversity among large-bodied forms in the past, mirroring studies on dental microwear and tooth enamel isotopes showing that large Pleistocene kangaroos exhibited a greater diversity of diets and habitat preferences than today (DeSantis et al. 2017), and echoing the greater locomotor diversity apparent in smaller kangaroos during the Miocene (Den Boer et al. 2019).

The morphology of the distal humerus reflects the degree of pronation and supination of the forearm, maneuverability important in arboreal mammals but reduced in terrestrial mammals, where stabilization of the joint takes priority. In arboreal taxa, there is a high degree of mobility of the elbow in pronation/supination, while in terrestrial taxa, movement at the elbow is more restricted, limiting (to a greater or lesser extent) the forelimb to a prone position. This observed behavior in mammals specialized for different substrates is reflected in the morphology of the distal humerus articulation, emphasizing (respectively) maneuverability over stability at the elbow joint. Nevertheless, many non-ungulate terrestrial taxa retain sufficient forearm maneuverability for a degree of food manipulation (Figueirido et al. 2016).

The saltating kangaroos encompass a broad range of specializations, reflected in their range of scores on the first component of the principal components analysis (Fig. 5a). The small, predominantly quadrupedal macropodids such as $S$. brachyurus $(\# 67,68)$ and D. luctuosa $(\# 46)$ have negative scores (indicative of moderate forearm mobility), while the large specialized hoppers such as $O$. rufus (\#59) and M. giganteus (\#51) have positive scores (indicative of high forearm mobility), overlapping with the tree-kangaroos (Dendrolagus spp., \#40-45) in the morphospace. However, this morphology in large macropodines may not reflect forelimbs optimized for mobility so much as forelimbs released from some of the demands of weight-bearing during slow locomotion; these large macropodines engage in pentapedal locomotion in which support of the body weight is shared between the forelimbs and the tail as the hindlimbs swing forward (Dawson et al. 2015). Note, however, that large fossil species of Macropus (M. ferragus, \#50, and Macropus sp., \#52) have slightly negative scores on PC1, clustering with the somewhat more quadrupedal extant kangaroos.

Sthenurines appear to have had a highly mobile forearm; they all fall within the morphospace of extant arboreal taxa on PC1, and a few of them have more positive scores than any extant kangaroo. It is hypothesized that sthenurines used their forelimbs to reach upwards for browse material (Wells and Tedford 1995), and their proximal humeral head resembles that of present-day suspensory mammals such as great apes and sloths (Janis et al. 2020), although note that many extinct, more terrestrial sloths have a different morphology (Toledo
Fig. 7 Canonical variates analyses performed on the 2D Procrustes coordinates of the distal humerus. Symbols differentiate taxa, shadings represent locomotor mode. Numbers identifying taxa shown in Appendix Table 1. a, CVA with saltatorial macropodoids added in separately as "unknowns" (extinct species of Macropus also included here, assumed to be saltatorial). b, CVA with all other extinct macropodoids added in separately as "unknowns". For families included in the superfamily groupings see the legend for Fig. 5
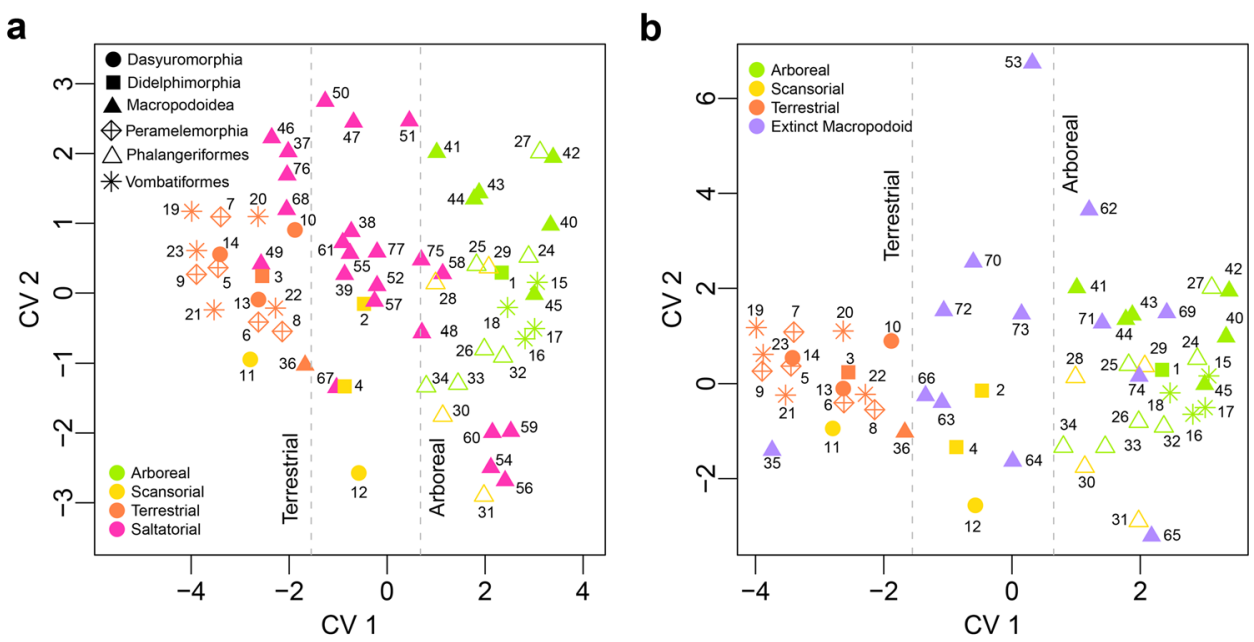
et al. 2012). A similarly-shaped proximal humerus is seen in both in the extant koala (which climbs via tree-hugging with extended forelimbs) and the Miocene diprotodontid Nimbadon, whose overall skeletal anatomy indicates an arboreal form of around 50-70 kg (and which also has a very arborealappearing distal humerus) (Black et al. 2012).

Additionally, sthenurines have a low brachial index (Jones 2020), reflecting elongation of the proximal forelimb; this represents an adaptation to more powerful movements of the forelimbs in grasping and pulling (Richards et al. 2015). Similar forelimb proportions are also seen in tree-kangaroos, which engage in extensive reaching during climbing (Warburton et al. 2011). Tree-kangaroos and sthenurines also resemble each other in one key aspect of proximal humeri morphology, even though they do not cluster together in terms the morphology seen in articular view: in both, the humeral head projects above the level of the tuberosities (Janis et al. 2020).

This same continuum of increasing forearm mobility from terrestrial, to scansorial, to arboreal is also reflected in the distribution of taxa along the first canonical variates axis (Fig. 7). Macropodoids follow this general continuum; quadrupedal (obligate and habitual) taxa (e.g., $S$. brachyurus) have more negative scores, and large saltators and sthenurines have more positive ones. Most Protemnodon species plot on the negative end of this continuum, as does the balbarid $G$. gillespieae (\#35), reflecting a greater degree of forelimb stabilization. Den Boer et al. (2019), proposed that G. gillespieae was terrestrial, based on the morphology of its astragalus and pedal digit IV ungual. Our results support this claim, with the forearm morphology of this stem macropodoid also reflecting a more terrestrial, quadrupedal gait. P. otibandus (\#65), a small ( $50 \mathrm{~kg}$; Flannery 1994) species of Protemnodon from New Guinea (Dawson 2004), plots on the arboreal end of the CVA, implying a high degree of forearm mobility. As with other species of Protemnodon, little is known of the ecomorphology of P. otibandus; however, unlike the larger species, these small New Guinean species of Protemnodon have short tibiae, similar to those of tree-kangaroos (Kear et al. 2008). Kear et al. (2008) proposed that species of Protemnodon were adapted for a number of primary gaits; results here support this notion. Consequently, as this study focused on large species of Protemnodon, further analysis on the smaller species is required, although there is currently little postcranial material available for study.

In both the PCA and the CVA, Protemnodon species plot distant from $O$. rufus and $M$. giganteus, indicating divergence in locomotor mode. The distal humerus of large Protemnodon species possesses a capitular tail and a long trochlear crest (Figs. 4 and 6), reflected in the negative position of these taxa on PC2; both features would increase forelimb stabilization (Figueirido et al. 2016). Large Protemnodon species cluster with the wombats, the only extant fully-terrestrial quadrupedal diprotodontids. Thus, the distal humeral morphology of the large species of Protemnodon reflects a more stable joint with a greater capacity for weight-bearing than extant macropodids, and the forearm would have been more restricted to parasagittal motion than the forearm of extant large macropodines.

These results support the notion that large species of Protemnodon may have been predominantly quadrupedal (Den Boer 2018) and corroborate the results of Janis et al. (2020), who found that the proximal humeral morphology of large Protemnodon species is also indicative of more extensive weight-bearing on the forelimbs than extant macropodids. However, despite being closely related to the pentapedally-locomoting Macropus and Osphranter (Llamas et al. 2015), Protemnodon is unlikely to have locomoted in this fashion. Pentapedal locomotion has been adopted by large extant macropodines to allow quadrupedal gaits in animals with very long hindlimbs (Dawson et al. 2015) and, as previously noted, pentapedal locomotion is more expensive than quadrupedal locomotion. Large species of Protemnodon had shorter hindlimbs and more robust forelimbs than their extant relatives (Den Boer 2018; Jones 2020), both of which would benefit some form of quadrupedal locomotion that did not engage the tail. Protemnodon also had a relatively large sacrum (CMJ personal observation, unnumbered specimen of $P$. brehus in the South Australian Museum), suggestive of significantly different forces through the hindlimbs than in other kangaroos. Additionally, the morphology of the first caudal vertebra in $P$. anak (CMJ personal observation, NMV P39105) suggests that it lacked the morphological features seen in large extant kangaroos that draw the tail under the body during pentapedal locomotion (see Dawson 2015). A greater reliance on quadrupedal locomotion in Protemnodon may have come at the expense of anatomy specialized for hopping (i.e., long metatarsals), but may have been an economical way of life for a predominantly closed-habitat (DeSantis et al. 2017) large kangaroo.

A recent study of a large Pleistocene macropodine with similar cranial morphology to Protemnodon, Congruus kitcheneri, which may be closely related to this taxon (Prideaux and Warburton 2010), proposed this animal to be semi-arboreal (Warburton and Prideaux 2021). We were not able to include this taxon in our analysis, but we note that its distal humeral morphology certainly resembles that of arboreal extant kangaroos and is not at all similar to that of Protemnodon.

Finally, we know little about the locomotion of the giant Pleistocene species of Macropus, whose size alone (especially the newly discovered unnamed species; Hocknull et al. 2020) would appear to be prohibitive of hopping. The distal humeral morphology of the two individuals included 
here suggests that they, too, might have been more reliant on quadrupedal gaits than their smaller extant congeneric species, but further investigation is clearly needed.

\section{Conclusions}

Extinct "giant" kangaroos have long been considered scaledup versions of extant kangaroos, with similar patterns of locomotion: quadrupedal (or pentapedal) locomotion at slow gaits and hopping at faster gaits. Our study here on distal humeri shows that both sthenurines, and at least the larger species of the macropodine Protemnodon, appear to have had different modes of at least slow locomotion than extant large macropodines (echoing the study on the proximal humerus by Janis et al. 2020). The humeri of sthenurines are, in general, more like those of arboreal forms than those of the extant saltating kangaroos, supporting the prior hypothesis that sthenurines did not employ a locomotor gait that involved bearing weight on the forelimbs. In contrast, the large Protemnodon species have a distal humerus like terrestrial forms, supporting the prior hypothesis that they were more quadrupedal than their extant macropodine relatives.

Supplementary Information The online version contains supplementary material available at https://doi.org/10.1007/s10914-021-09576-3.

Acknowledgements We thank Ben Moon, Tom Stubbs, and Nuria Melisa Morales García for help with the phylogenetic analyses, and Kieran Mitchell for supplying phylogenies. We thank Hazel Richards, Isaac Kerr and Mathew Lowe for providing some additional photographs (of Protemnodon anak, Protemnodon otibandus and Osphranter rufus, respectively). We thank numerous museum curators for access to specimens in their care, including Ross McPhee, Rob Voss, and Eileen Westwig (Mammalogy) and Jin Meng and Judy Galkin (Vertebrate Paleontology) at the American Museum of Natural History, New York, NY; Hopi Hoekstra, Judy Chupasko, and Mark Omura at the Harvard Museum of Comparative Zoology, Cambridge, MA; Bill Clemens and
Pat Holroyd at the University Museum of California, Berkeley, CA; Pip Brewer and Nadine Gabriel at the Natural History Museum, London, UK; Rob Asher and Mathew Lowe at the University of Cambridge Museum of Zoology, Cambridge, UK; Mary-Anne Binnie and David Stemmer at the South Australian Museum, Adelaide, Australia; Scott Hocknell and Kristen Spring at the Queensland Museum, Brisbane, Australia; and Karen Roberts and Tim Ziegler at the Museum Victoria, Melbourne, Australia. Some of these data were collected under the auspices of a Marie Curie Foundation Incoming Fellowship 623328 to $\mathrm{CMJ}$, and $\mathrm{BJ}$ received some travel funding from the University of Bristol program in Palaeobiology (this MS originally formed part of BJ's Master's thesis in that program).

Authors' Contributions CMJ conceived of the project and collected the photographic data; BJ and AM-S conducted the analyses, and both prepared the illustrations; all authors contributed to the writing of the paper.

Funding The authors received no direct funding for this contribution, although this formed part of the project of a Master's thesis for BJ, with some funds from the University of Bristol Program in Palaeobiology.

Availability of Data The datasets generated and/or analyzed during the current study can be found via the University of Bristol depository. DOI: https://doi.org/10.5523/bris.1iq521byblyqg2oqrja7twya6z

Code Availability The R code generated during the current study can be found via the University of Bristol depository.

\section{Declarations}

Conflicts of Interest/Competing Interests The authors declare that they have no conflicts of interests.

Open Access This article is licensed under a Creative Commons Attribution 4.0 International License, which permits use, sharing, adaptation, distribution and reproduction in any medium or format, as long as you give appropriate credit to the original author(s) and the source, provide a link to the Creative Commons licence, and indicate if changes were made. The images or other third party material in this article are included in the article's Creative Commons licence, unless indicated otherwise in a credit line to the material. If material is not included in the article's Creative Commons licence and your intended use is not permitted by statutory regulation or exceeds the permitted use, you will need to obtain permission directly from the copyright holder. To view a copy of this licence, visit http://creativecommons.org/licenses/by/4.0/. 


\section{Appendix Table 1 - Specimens Used in the Analysis of Distal Humeral Morphology}

\begin{tabular}{|c|c|c|c|c|c|}
\hline Taxon ID & Taxon & Spec. \# & $\begin{array}{l}\text { Family or } \\
\text { Subfamily }\end{array}$ & Loc. & Common Name \\
\hline 1 & Caluromys lanatus & MCZ 37857 & Didelphidae & A & $\begin{array}{l}\text { Brown-eared } \\
\text { woolly opossum }\end{array}$ \\
\hline 2 & Didelphis virginiana & MCZ 62199 & Didelphidae & $\mathrm{Sa}$ & Virginia opossum \\
\hline 3 & Metachirus nudicaudatus & MCZ 167 & Didelphidae & $\mathrm{T}$ & $\begin{array}{l}\text { Brown four-eyed } \\
\text { opossum }\end{array}$ \\
\hline 4 & Philander opossum & MCZ 37851 & Didelphidae & $\mathrm{Sa}$ & $\begin{array}{l}\text { Gray four-eyed } \\
\text { opossum }\end{array}$ \\
\hline 5 & Macrotis lagotis & AMNH 35685 & Thylacomyidae & $\mathrm{T}$ & Greater bilby \\
\hline 6 & Macrotis lagotis & MCZ 31095 & Thylacomyidae & $\mathrm{T}$ & Greater bilby \\
\hline 7 & Isoodon obesulus & UCMP 77305 & Peramelidae & $\mathrm{T}$ & $\begin{array}{l}\text { Southern brown } \\
\text { bandicoot }\end{array}$ \\
\hline 8 & Perameles bougainville & MCZ 52970 & Peramelidae & $\mathrm{T}$ & $\begin{array}{l}\text { Western barred ban- } \\
\text { dicoot }\end{array}$ \\
\hline 9 & Perameles nasuta & AMNH 65659 & Peramelidae & $\mathrm{T}$ & $\begin{array}{l}\text { Long-nosed ban- } \\
\text { dicoot }\end{array}$ \\
\hline 10 & $\dagger$ Thylacinus cynocephalus & MCZ 36797 & $\dagger$ Thylacinidae & $\mathrm{T}$ & Thylacine \\
\hline 11 & Dasyurus geoffroii & MCZ 6932 & Dasyuridae & St & Western quoll \\
\hline 12 & Dasyurus maculatus & AMNH 66162 & Dasyuridae & St & Tiger quoll \\
\hline 13 & Sarcophilus harrisi & AMNH 35634 & Dasyuridae & $\mathrm{T}$ & Tasmanian devil \\
\hline 14 & Sarcophilus harrisi & AMNH 65672 & Dasyuridae & $\mathrm{T}$ & Tasmanian devil \\
\hline 15 & Phascolarctos cinereus & AMNH 42903 & Phascolarctidae & A & Koala \\
\hline 16 & Phascolarctos cinereus & AMNH 65607 & Phascolarctidae & A & Koala \\
\hline 17 & Phascolarctos cinereus & AMNH 107805 & Phascolarctidae & A & Koala \\
\hline 18 & Phascolarctos cinereus & MCZ 5821 & Phascolarctidae & A & Koala \\
\hline 19 & Vombatus ursinus & AMNH 35512 & Vombatidae & $\mathrm{T}$ & Common wombat \\
\hline 20 & Vombatus ursinus & AMNH 35701 & Vombatidae & $\mathrm{T}$ & Common wombat \\
\hline 21 & Vombatus ursinus & AMNH 66197 & Vombatidae & $\mathrm{T}$ & Common wombat \\
\hline 22 & Vombatus ursinus & AMNH 146850 & Vombatidae & $\mathrm{T}$ & Common wombat \\
\hline 23 & Vombatus ursinus & MCZ 2586 & Vombatidae & $\mathrm{T}$ & Common wombat \\
\hline 24 & Phalanger celebensis & AMNH 146805 & Phalangeridae & A & $\begin{array}{l}\text { Sulawesi dwarf } \\
\text { cuscus }\end{array}$ \\
\hline 25 & Phalanger orientalis & AMNH 80933 & Phalangeridae & A & $\begin{array}{l}\text { Northern common } \\
\text { cuscus }\end{array}$ \\
\hline 26 & Phalanger sericus & AMNH 191203 & Phalangeridae & A & Silky cuscus \\
\hline 27 & Strigocuscus pelengensis & AMNH 108000 & Phalangeridae & A & Banggai cuscus \\
\hline 28 & Trichosurus arnhemensis & AMNH 197668 & Phalangeridae & $\mathrm{Sa}$ & $\begin{array}{l}\text { Northern brushtail } \\
\text { possum }\end{array}$ \\
\hline 29 & Trichosurus caninus & AMNH 65535 & Phalangeridae & $\mathrm{Sa}$ & Short-eared possum \\
\hline 30 & Trichosurus vulpecula & AMNH 35708 & Phalangeridae & $\mathrm{Sa}$ & $\begin{array}{l}\text { Common brushtail } \\
\text { possum }\end{array}$ \\
\hline 31 & Trichosurus vulpecula & AMNH 65597 & Phalangeridae & $\mathrm{Sa}$ & $\begin{array}{l}\text { Common brushtail } \\
\text { possum }\end{array}$ \\
\hline 32 & Dactylopsila palpator & AMNH 194759 & Petauridae & A & Long-fingered triok \\
\hline 33 & Petaurus norfolkensis & AMNH 35763 & Petauridae & A & Squirrel glider \\
\hline 34 & Pseudochirus peregrinus & UCMP 84683 & Pseudocheiridae & A & $\begin{array}{l}\text { Common ringtail } \\
\text { possum }\end{array}$ \\
\hline 35 & $\dagger$ Ganawamaya gillespieae & QMF 34532 & $\dagger$ Balbaridae & Uk & Extinct \\
\hline 36 & Hypsiprymnodon moschatus & SAM M11940 & Hypsiprymnodontidae & $\mathrm{T}$ & Musky rat-kangaroo \\
\hline 37 & Aepyprymnus rufescens & SAM M9017 & Potoroidae & SL & $\begin{array}{l}\text { Rufous rat-kan- } \\
\text { garoo }\end{array}$ \\
\hline
\end{tabular}




\begin{tabular}{|c|c|c|c|c|c|}
\hline Taxon ID & Taxon & Spec. \# & $\begin{array}{l}\text { Family or } \\
\text { Subfamily }\end{array}$ & Loc. & Common Name \\
\hline 38 & Bettongia lesueur & AMNH 119489 & Potoroidae & SL & Boodie \\
\hline 39 & Potorous longipes & NMV C32723 & Potoroidae & SL & $\begin{array}{l}\text { Long-footed } \\
\text { potoroo }\end{array}$ \\
\hline 40 & Dendrolagus dorianus & AMNH 192143 & Macropodinae & A & $\begin{array}{l}\text { Doria's tree-kan- } \\
\text { garoo }\end{array}$ \\
\hline 41 & Dendrolagus goodfellowi & NMV C25092 & Macropodinae & A & $\begin{array}{l}\text { Goodfellow's tree- } \\
\text { kangaroo }\end{array}$ \\
\hline 42 & Dendrolagus lumholtzi & AMNH 35642 & Macropodinae & A & $\begin{array}{l}\text { Lumholtz's tree- } \\
\text { kangaroo }\end{array}$ \\
\hline 43 & Dendrolagus lumholtzi & AMNH 65248 & Macropodinae & A & $\begin{array}{l}\text { Lumholtz's tree- } \\
\text { kangaroo }\end{array}$ \\
\hline 44 & Dendrolagus lumholtzi & AMNH 65261 & Macropodinae & A & $\begin{array}{l}\text { Lumholtz's tree- } \\
\text { kangaroo }\end{array}$ \\
\hline 45 & Dendrolagus lumholtzi & SAM M7206 & Macropodinae & A & $\begin{array}{l}\text { Lumholtz's tree- } \\
\text { kangaroo }\end{array}$ \\
\hline 46 & Dorcopsis luctuosa & SAM M15178 & Macropodinae & SL & Gray dorcopsis \\
\hline 47 & Dorcopsis muelleri & MCZ 222626 & Macropodinae & SL & Brown dorcopsis \\
\hline 48 & Lagorchestes hirsutus & SAM M3590 & Macropodinae & SL & $\begin{array}{l}\text { Rufous hare- } \\
\text { wallaby }\end{array}$ \\
\hline 49 & Lagostrophus fasciatus & WAM 22911 & Lagostrophinae & SL & $\begin{array}{l}\text { Banded hare- } \\
\text { wallaby }\end{array}$ \\
\hline 50 & Macropus †ferragus & NMV P28290 & Macropodinae & SL & Extinct \\
\hline 51 & Macropus giganteus & AMNH 35747 & Macropodinae & SL & $\begin{array}{l}\text { Eastern grey kan- } \\
\text { garoo }\end{array}$ \\
\hline 52 & Macropus sp. (large fossil) & SAM FNA 112 & Macropodinae & SL & Extinct \\
\hline 53 & $\dagger$ Metasthenurus maddocki & SAM P17529 & $\dagger$ Sthenurinae & Uk & Extinct \\
\hline 54 & Notamacropus dorsalis & NMV C6490 & Macropodinae & SL & $\begin{array}{l}\text { Black-striped wal- } \\
\text { laby }\end{array}$ \\
\hline 55 & Notamacropus eugenii & CMJ (unb) & Macropodinae & SL & Tammar wallaby \\
\hline 56 & Notamacropus rufogriseus & AMNH 65121 & Macropodinae & SL & Red-necked wallaby \\
\hline 57 & Onychogalea fraenata & SAM M24347 & Macropodinae & SL & $\begin{array}{l}\text { Bridled nail-tail } \\
\text { wallaby }\end{array}$ \\
\hline 58 & Osphranter robustus & AMNH 70323 & Macropodinae & SL & Common wallaroo \\
\hline 59 & Osphranter rufus & UCMZ A12-21-3 & Macropodinae & SL & Red kangaroo \\
\hline 60 & Petrogale godmani & SAM M7189 & Macropodinae & SL & $\begin{array}{l}\text { Godman's rock- } \\
\text { wallaby }\end{array}$ \\
\hline 61 & Petrogale herberti & AMNH 65241 & Macropodinae & SL & $\begin{array}{l}\text { Herbert's rock- } \\
\text { wallaby }\end{array}$ \\
\hline 62 & $\dagger$ Procoptodon gilli & SAM P18323 & $\dagger$ Sthenurinae & Uk & Extinct \\
\hline 63 & $\dagger$ Protemnodon anak & NMV P39105 & Macropodinae & Uk & Extinct \\
\hline 64 & $\dagger$ Protemnodon anak & NMV P229318 & Macropodinae & Uk & Extinct \\
\hline 65 & $\dagger$ Protemnodon otibandus & UCMP 70059 & Macropodinae & Uk & Extinct \\
\hline 66 & $\dagger$ Protemnodon sp. & NHMUK PV (unb) & Macropodinae & Uk & Extinct \\
\hline 67 & Setonix brachyurus & AMNH 160043 & Macropodinae & SL & Quokka \\
\hline 68 & Setonix brachyurus & NMV C23029 & Macropodinae & SL & Quokka \\
\hline 69 & $\dagger$ Simosthenurus occidentalis & SAM P17476 & $\dagger$ Sthenurinae & Uk & Extinct \\
\hline 70 & $\dagger$ Sthenurus andersoni & SAM P13673 & $\dagger$ Sthenurinae & Uk & Extinct \\
\hline 71 & $†$ Sthenurus sp. & WAM 64-12-14 & $†$ Sthenurinae & Uk & Extinct \\
\hline 72 & $\dagger$ Sthenurus stirlingi & AMNH 117494 & $\dagger$ Sthenurinae & Uk & Extinct \\
\hline 73 & $\dagger$ Sthenurus stirlingi & AMNH 117498 & $\dagger$ Sthenurinae & Uk & Extinct \\
\hline 74 & $\dagger$ Sthenurus stirlingi & SAM P22533 & $\dagger$ Sthenurinae & Uk & Extinct \\
\hline 75 & Thylogale billardierii & AMNH 65215 & Macropodinae & $\mathrm{S}$ & $\begin{array}{l}\text { Tasmanian pade- } \\
\text { melon }\end{array}$ \\
\hline
\end{tabular}




\begin{tabular}{|c|c|c|c|c|c|}
\hline Taxon ID & Taxon & Spec. \# & $\begin{array}{l}\text { Family or } \\
\text { Subfamily }\end{array}$ & Loc. & Common Name \\
\hline$\overline{76}$ & Thylogale stigmatica & AMNH 65153 & Macropodinae & $\mathrm{S}$ & $\begin{array}{l}\text { Red-legged pade- } \\
\text { melon }\end{array}$ \\
\hline 77 & Wallabia bicolor & AMNH 65125 & Macropodinae & S & Swamp wallaby \\
\hline
\end{tabular}

Lagostrophinae, Macropodinae, and Sthenurinae are all subfamilies of the Macropodidae. Key to abbreviations of locomotor mode (Loc.) $A$ arboreal, $S a$ scansorial, predominantly arboreal, $S t$ scansorial, predominantly terrestrial, $T$ terrestrial, $S L$ saltatorial, $U k$ unknown, $\dagger$ an extinct taxon, Key to museum acronyms: AMNH American Museum of Natural History (New York, USA), CMJ personal collection of Christine Janis (specimen of natural skull from Skulls Unlimited), MCZ Museum of Comparative Zoology (Harvard University, USA), NHM Natural History Museum, London (UK), QMF Queensland Museum fossil collection (Brisbane, Australia), SAM South Australian Museum (Adelaide, Australia), UCMP University of California Museum of Paleontology (Berkeley, USA), UCMZ University of Cambridge Museum of Zoology, Cambridge, UK., WAM Western Australian Museum (Perth, Australia). (unb unnumbered)

\section{Appendix Table 2 Description of the Location of the Landmarks Used in this Analysis}

\begin{tabular}{ll}
\hline Landmark & Description of location \\
\hline 1 & Proximomedial border of the trochlea \\
2 & Highest (most proximal) point of the trochlea \\
3 & Proximal border between capitulum and trochlea \\
4 & Highest (most proximal) point of the capitulum \\
5 & Proximolateral border of capitulum (capitular tail) \\
6 & Distomedial border of the trochlea \\
7 & Distal border between capitulum and trochlea \\
8 & Deepest (most distal) point of the capitulum \\
9 & Laterodistal border of the capitulum \\
\hline
\end{tabular}

\section{References}

Adams DC (2014) A generalized K statistic for estimating phylogenetic signal from shape and other high-dimensional multivariate data. Syst Biol 63:685-697. https://doi.org/10.1093/sysbio/syu030

Adams DC, Collyer ML, Kaliontzopoulou A, Sherratt E (2016) Geomorph: software for geometric morphometric analyses. R package version 3.0.5. https://github.com/geomorphR/geomorph

Andersson K, Werdelin L (2003) The evolution of cursorial carnivores in the Tertiary: implications of elbow-joint morphology. Proc R Soc Biol Sci 270:S163-S165. https://doi.org/10.1098/rsbl.2003. 0070

Argot C (2001). Functional-adaptive anatomy of the forelimb in the Didelphidae, and the paleobiology of the Paleocene marsupials Mayulestes ferox and Pucadelphys andinus. J Morphol 247:51-79

Bennett M (2000) Unifying principles in terrestrial locomotion: do hopping Australian marsupials fit in? Physiol Biochem Zool 73:726-735. https://doi.org/10.1086/318110

Bennett MB, Taylor CR (1995) Scaling of elastic strain energy in kangaroos and the benefits of being big. Nature 378:56-59. https:// doi.org/10.1038/378056a0

Black KH, Camens AB, Archer M, Hand SJ (2012) Herds overhead: Nimbadon lavarackorum (Diprotodontidae), heavyweight marsupial herbivores in the Miocene forests of Australia. PLoS One 7:e48213. https://doi.org/10.1371/journal.pone.0048213

Camens AB, Worthy TH (2019) Walk like a kangaroo: new fossil trackways reveal a bipedally striding macropodid in the Pliocene of Central Australia. J Vertebr Paleontol, Programs and Abstracts 2019:72
Chen M, Wilson GP (2015) A multivariate approach to infer locomotor modes in Mesozoic mammals. Paleobiology 4:280-312. https:// doi.org/10.1017/pab.2014.14

Couzens AM, Prideaux GJ (2018) Rapid Pliocene adaptive radiation of modern kangaroos. Science 362:72-75. https://doi.org/10.1126/ science.aas 8788

Dawson L (2004) A new fossil genus of forest wallaby (Marsupialia, Macropodinae) and a review of Protemnodon from eastern Australia and New Guinea. Alcheringa 28:275-290. https://doi.org/ $10.1080 / 03115510408619285$

Dawson RS (2015) Morphological correlates of pentapedal locomotion in kangaroos and wallabies (Family: Macropodidae). Dissertation, The University of Western Australia, Perth

Dawson RS, Warburton NM, Richards HL, Milne N (2015) Walking on five legs: investigating tail use during slow gait in kangaroos and wallabies. Aust J Zool 63:192-200. https://doi.org/10.1071/ZO15007

Den Boer W (2018) Evolutionary progression of the iconic Australasian kangaroos, rat-kangaroos, and their fossil relatives (Marsupiala: Macropodiformes). Dissertation, Uppsala University, Uppsala

Den Boer W, Campione NE, Kear BP (2019) Climbing adaptations, locomotory disparity and ecological convergence in ancient stem 'kangaroos'. R Soc Open Sci 6:181617. https://doi.org/10.1098/ rsos. 181617

DeSantis LRG, Field JH, Wroe S, Dodson JR (2017) Dietary responses of Sahul (Pleistocene Australia-New Guinea) megafauna to climate and environmental change. Paleobiology 43:181-185. https://doi.org/10.1017/pab.2016.50

Doube M, Felder AA, Chua MY, Lodhia K, Koslowski MM, Hutchinson JR, Shefelbine, SJ (2018) Limb bone scaling in hopping 
macropods and quadrupedal artiodactyls. $R$ Soc Open Sci 5: 180152. https://doi.org/10.1098/rsos.180152

Figueirido B, Martín-Serra A, Janis CM (2016) Ecomorphological determinations in the absence of living analogues: the predatory behavior of the marsupial lion (Thylacoleo carnifex) as revealed by elbow joint morphology. Paleobiology 42:508-531. https://doi. org/10.1017/pab.2015.55

Flannery TF (1994) The fossil land mammal record of New Guinea: a review. Sci New Guinea 20:39-48

Gould FDH (2017) Testing the role of cursorial specializations as adaptive key innovations in Paleocene-Eocene ungulates. J Mammal Evol 24:453-463. https://doi.org/10.1007/s10914-016-9359-4

Helgen KM, Wells RT, Kear BP, Gerdtz WR, Flannery TF (2006) Ecological and evolutionary significance of sizes of giant extinct kangaroos. Aust J Zool 54:293-303. https://doi.org/10.1071/ZO05077

Hildebrand M, Goslow G (1982) Analysis of Vertebrate Structure. Wiley, New Jersey

Hocknull SA, Lewis R, Arnold LJ, Pietsch T, Joannes-Boyau R, Price GJ, Moss P, Wood R, Dosseto A, Louys J et al. (2020) Extinction of eastern Sahul megafauna coincides with sustained environmental deterioration. Nat Commun 11:1-14. https://doi.org/10.1038/ s41467-020-15785-w

Janis CM, Martín-Serra A (2020) Postcranial elements of small mammals as indicators of locomotion and habitat. PeerJ, 8:p.e9634. https://doi.org/10.7717/peerj.9634

Janis CM, Buttrill K, Figueirido B (2014) Locomotion in extinct giant kangaroos: were sthenurines hop-less monsters? PLoS One 9(10): e109888. https://doi.org/10.1371/journal.pone.0109888

Janis CM, Napoli JG, Billingham C, Martín-Serra A (2020) Proximal humerus morphology indicates divergent patterns of locomotion in extinct giant kangaroos. J Mammal Evol 27:627-647 https:// doi.org/10.1007/s10914-019-09494-5

Jenkins FA Jr (1973) The functional anatomy and evolution of the mammalian humero-ulnar articulation. Am J Anat 137:281-298. https://doi.org/10.1002/aja.1001370304

Jones B (2020) Locomotor divergence in Macropodoidea: Protemnodon was not a giant hopping kangaroo. Masters' thesis, University of Bristol, Bristol, UK

Kear BP, Cook BN, Archer M, Flannery TF (2007) Implications of a new species of the Oligo-Miocene kangaroo (Marsupialia: Macropodoidea) Nambaroo, from the Riversleigh World Heritage Area, Queensland, Australia. J Paleontol 81:1147-1167.

Kear BP, Lee MSY, Gerdtz WR, Flannery TF (2008) Evolution of hind limb proportions in kangaroos (Marsupalia: Macropodoidea). In: Sargis EF, Dagosto M (eds) Mammalian Evolutionary Morphology: A Tribute to Frederick S. Szalay. Springer, New York, pp 25-55

Klingenberg CP (2011) MorphoJ: an integrated software package for geometric morphometrics. Available at http://www.flywings.org. uk/MorphoJ_page.htm

Klingenberg CP, Monteiro LR (2005) Distances and directions in multidimensional shape spaces: implications for morphometric applications. Syst Biol 54:678-688. https://doi.org/10.1080/10635 150590947258

Llamas B, Brotherton P, Mitchell KJ, Templeton JEL, Thomson VA, Metcalf JL, Armstrong KN, Kasper M, Richards SM, Camens AB, Lee MSY, Cooper A (2015) Late Pleistocene Australian marsupial DNA clarifies the affinities of extinct megafaunal kangaroos and wallabies. Mol Biol Evol 32:574-584. https://doi.org/10.1093/ molbev/msu338

McGowan CP, Skinner J, Biewener AA (2008) Hind limb scaling of kangaroos and wallabies (superfamily Macropodoidea): implications for hopping performance, safety factor, and elastic scaling. J Anat 212:153-163. https://doi.org/10.1111/j.1469-7580.2007. 00841.x

Meredith RW, Westerman M, Springer MS (2008) A phylogeny and timescale for the living genera of kangaroos and kin (Macropodiformes: Marsupialia) based on nuclear DNA sequences. Aust J Zool 56:395-410. https://doi.org/10.1071/ $\mathrm{ZO} 08044$

Mittroecker P, Bookstein F (2011) Linear discrimination, ordination, and the visualization of selection gradients in modern morphometrics. Evol Biol 38:100-114. https://doi.org/10.1007/ s11692-011-9109-8

O'Connor S, Dawson T, Kram R, Donelan J (2014) The kangaroo's tail propels and powers pentapedal locomotion. Biol Lett 10: 20140381. https://doi.org/10.1098/rsbl.2014.0381

Polly PD (2007) Limbs in mammalian evolution. In Hall BH (ed) Fins into Limbs: Evolution, Development and Transformation. University of Chicago Press, Chicago, pp 245-268

Prideaux GJ, Warburton NM (2010) An osteology-based appraisal of the phylogeny and evolution of kangaroos and wallabies (Macropodidae: Marsupialia). Zool J Linnean Soc 159: 954-987. https://doi.org/10.1111/j.1096-3642.2009.00607.x

Richards H, Grueter C, Milne N (2015) Strong arm tactics: sexual dimorphism in macropodid limb proportions. J Zool 297:123-131. https://doi.org/10.1111/jzo.12264

Rohlf F (2004) TpsDig. Department of Ecology and Evolution, State University of New York, Stony Brook, NY

R Core Team (2020) R: a language and environment for statistical computing. Version 3.4.1. R Foundation for Statistical Computing, Vienna. Available at http://cran.R-project.org

Samuels JX, Van Valkenburgh B (2008) Skeletal indicators of locomotor adaptations in living and extinct rodents. J Morphol 269:13871411. https://doi.org/10.1002/jmor.10662

Snelling EP, Biewener AA, Hu Q, Taggart DA, Fuller A, Mitchell D, Maloney SK, Seymour RS (2017) Scaling of the ankle extensor muscle-tendon units and the biomechanical implications for bipedal hopping locomotion in the post-pouch kangaroo Macropus fuliginousus. J Anat 231:921-930. https://doi.org/10.1111/ joa. 12715

Szalay FS, Sargis EJ (2001) Model-based analysis of postcranial osteology of marsupials of Palaeocene of Itaboraí (Brazil) and the phylogenetics and biogeography of Metatheria. Geodiversitas 23:139-302

Taylor ME (1974) The functional anatomy of the forelimb of some African Viverridae (Carnivora). J Morphol 143:307-336. https:// doi.org/10.1002/jmor.1051430305

Toledo N, Bargo MN, Cassini GH, Vizcaíno, SF (2012) The Forelimb of Early Miocene Sloths (Mammalia, Xenarthra, Folivora): Morphometrics and Functional Implications for Substrate Preferences. J Mammal Evol 19:185-198. https://doi.org/10.1007/ s10914-012-9185-2

Van Valkenburgh B (1985) Locomotor diversity within past and present guilds of large predatory mammals. Paleobiology 11, 406-428. https://doi.org/10.1017/S0094837300011702

Wagstaff AY (2018) The biomechanics of kangaroo feet: hopping for a better resolution. Masters' thesis, University of Bristol, Bristol, $\mathrm{UK}$

Warburton NM, Prideaux, GJ (2021) The skeleton of Congruus kitcheneri, a semiarboreal kangaroo from the Pleistocene of southern Australia. R Soc Open Sci 8:202216. https://doi.org/10.1098/rsos. 202216

Warburton NM, Harvey KJ, Prideaux GJ, O'Shea JE (2011) Functional morphology of the forelimb of living and extinct tree-kangaroos (Marsupialia: Macropodidae). J Morphol 272:1230-1244. https:// doi.org/10.1002/jmor.10979

Wells RT, Tedford RH (1995) Sthenurus (Macropodidae, Marsupialia) from the Pleistocene of Lake Callabonna, South Australia. Bull Am Mus Nat Hist 225:1-111

Windsor DE, Dagg AI (1971) The gaits of the Macropodinae (Marsupialia). J Zool Lond 163:165-175 